\title{
DOES ASSISTIVE TECHNOLOGY HELP CHILDREN HAVING DISABILITIES IN MIDDLE EAST AND NORTH AFRICA (MENA) REGION: A LITERATURE REVIEW
}

\author{
AMAL. I. KHALIL ${ }^{1} \&$ NUSRATH YASMEEN ${ }^{2}$ \\ Professor Psychiatry and Mental Health Nursing Menoufia University, Egypt \\ King Saud Bin Abdul Aziz University for Health Sciences, College of Nursing, Jeddah \\ Faculty of Pharmacology, College of Nursing, King Saud Bin Abdul Aziz University for Health Sciences, Jeddah, Saudi Arabia
}

\begin{abstract}
For many children with disabilities (CWDs), normal/independent life becomes an issue. The social stigma prevailing disability often limits interactions, with their peers. Assistive technology (AT) can be utilized as a potential aid for overcoming their disabilities', compensating for their basic daily amenities and their educational requirement. The purpose of this review was to collect and corroborate information about various types or models of assistive technology. To compile this review various journals, books, electronic databases, and other resources were curated. The intent behind this review is to provide readers with a piece of in-depth knowledge about AT, the various resources available for utilization by children with disabilities (CWDs), and their parents. It also helps towards identifying critical issues about the various laws and policies related to $A T$ and their implementation. This review allows the policymakers, educational reformers, instructors, parents, and different stakeholders to consider AT as a significant tool and strive towards the integration of assistive technology in every walk of life.

KEYWORDS: Assistive Technology (AT), Children with Disabilities (CWDs), Assistive Devices, Literature Review, Professional Development
\end{abstract}

Received: Jun 09, 2020; Accepted: Jun 29, 2020; Published: Jun 30, 2020; Paper Id.: IJMPERDJUN2020305

\section{HIGHLIGHTS}

- Assistive technology is required to increase the quality of life of children with special needs.

- Usage of AT by CWDs is their basic right, as per records currently only $10 \%$ of the disabled people can utilize it.

- Collaboration and experimentation between policymakers and stakeholders are required to ensure the utilization of AT by CWDs for a better future.

\section{INTRODUCTION}

'Disability' is a complex human condition. Almost every individual is prone to experience either permanent or temporary disability at some point in life. As per the 2010 World Report on Disability, there are more than a billion people or about $15 \%$ of the world's populations are estimated to live with some form of disability. There is rapid growth in the percentage of people with disabilities. This growth is attributed to a drastic increase in the aging population, prevalence of chronic diseases globally such as cardiovascular diseases, and mental illness, an increase in impairments due to road traffic accidents, warfare, and natural disaster("World report on disability," n.d.). 
The disability may vary by the type of impairment, gender, and context hence it is not regarded as a homogenous category (Kuper et al, 2018).

According to the International Classification of Functioning Disability and Health (ICF) of the World Health Organization (WHO) disability is an 'umbrella term for impairments, activity limitations and participation restrictions' that relate to a health condition. These limitations, which interact with personal and contextual factors of the environment, result in disability(Kostanjsek, 2011). Hence, we can say that disability is not just a health problem but is a complex phenomenon, reflecting the interaction of having a condition-based limitation and experiencing barriers in the environment. It may include negative interactions between an individual with a health condition (e.g. cerebral palsy) and that individual's contextual (in other words, personal and environmental) factors associated with-not only with physical environment, but also social factors like culture, attitudes, economics, and policies that shape our life experiences(Krahn et al., 2015). These interactions with various barriers may hinder the full and effective participation of a person on an equal basis with other persons.

\section{METHODS}

This study is a research synthesis of the existing literature review. Studies published related to this topic from the time of inception to date were used. Search engines include Pub Med, Cochrane, Google Scholar, ERIC, Science Direct, Springer Link, Psych INFO, EBSCO host, and a university-owned database. The university database has a digital library, with free and full access to several esteemed journals and books. Keywords used for searching include "technology in education, assistive technology, equipment in the classroom, technology in special education, Assistive technology in MENA region".

\section{Prevalence of Disability in MENA Countries}

The number of disabled children persons all over the world was estimated by WHO and the World Bank accordingly found that more than a billion people live with some form of disability, which equates to approximately $15 \%$ of the world's population (Al-Dosari, (2016)). Among these, between 110 million (2.2\%) and 190 million (3.8\%) adults have very significant difficulties in functioning (Al-Dosari, (2016))

As regards the official and reliable sources of the exact number, unfortunately, there are no reliable and representative estimates based on actual measurement of the number of children with disabilities (Arezki. (2018a), AlDosari (2016)). On the other hand, the prevalence of childhood disability estimation is varying according to the differences in definitions and the adopted wide range of methodologies and measurement instruments (Al-Dosari, (2016), Arezki, et al. (2018a)). Additionally, the limitations of the census and general household surveys, the absence of registries in most lowand middle- income countries (LMICs), and poor access to culturally appropriate clinical and diagnostic services contribute to lower estimates (Arezki, et al. (2018a). As a result, many children with disabilities may neither be identified nor receive needed services.

Concerning the prevalence of childhood disability in Middle East North Africa (MENA) countries or the Arab world consists of 22 Arab countries located in the Middle East and North Africa (MENA). The countries included in MENA region are Algeria, Bahrain, the Comoros Islands, Djibouti, Egypt, Iraq, Jordan, Kuwait, Lebanon, Libya, Morocco, Mauritania, Oman, Palestine, Qatar, Saudi Arabia, Somalia, Sudan, Syria, Tunisia, the United Arab Emirates, and Yemen. Arabic is the predominant language here. There exists a tremendous diversity in terms of civil rights, immigration, and social integration, religion, culture, social norms, and civil conflict which impact social justice and the 


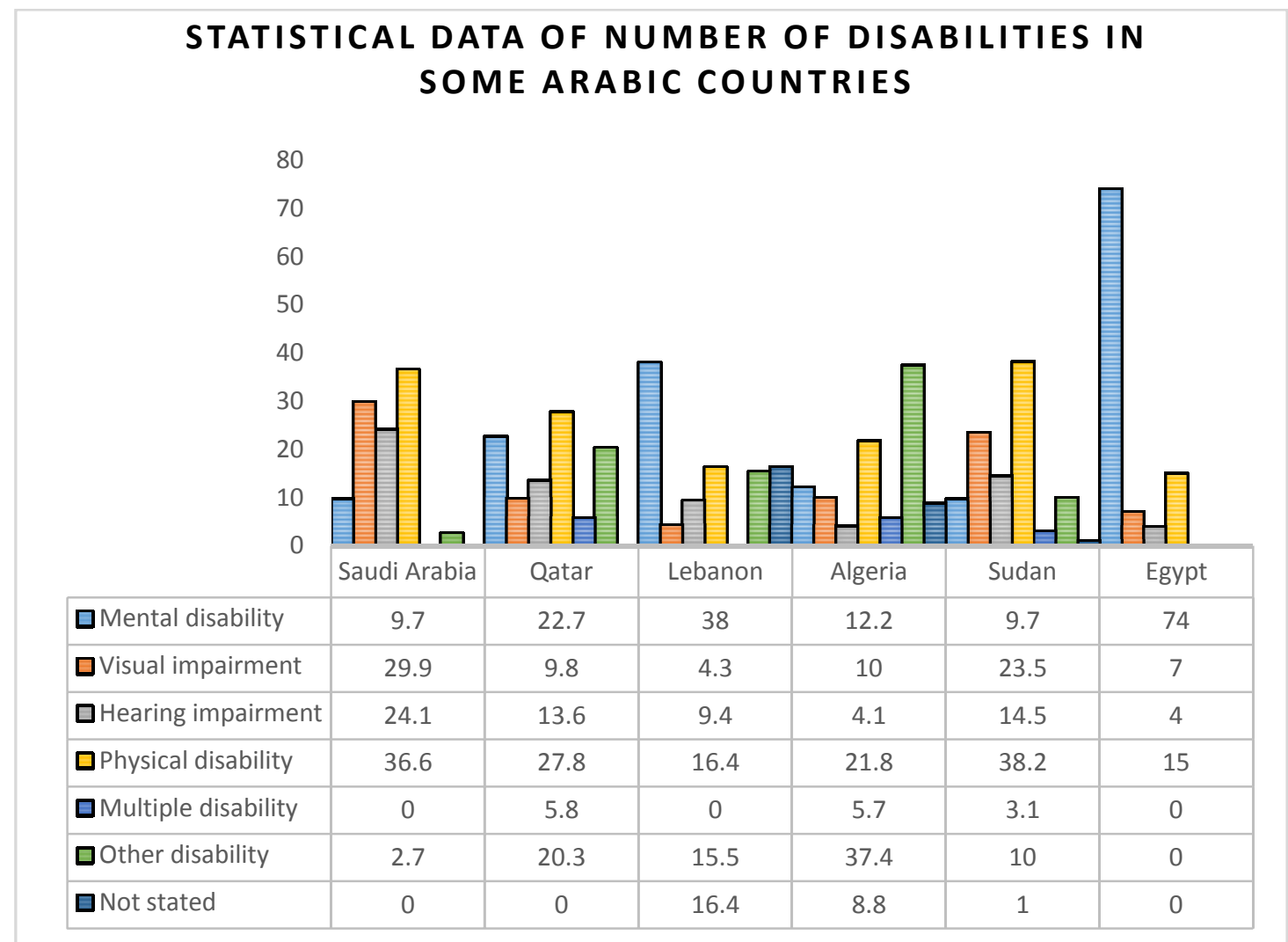

Figure 1: Statistical Data of Number of Disabilities in Some Arabic Countries.

Persons with disabilities (PWDs) are considered burdensome and shameful across the world with special reference to the Arab countries (Al Lawati, 2011). There is a social stigma associated with disclosing the disability of a person. This kind of social attitude towards disability is imperative as it has a direct impact on the quality of life of persons with disabilities (PWDs) their caregivers and families. These attitudes not only prevent these persons from getting appropriate services but also make it very hard for them and their families to lead a normal life.

\section{Disability in Children}

The Global Burden of Disease measures childhood disabilities (0-14 years), which is estimated to be 95 million (5.1\%) children, of whom 13 million (0.7\%) have "severe disability" ("The global burden of disease: 2004 update). Children with special health care needs (CSHCN), children with developmental disabilities (CWDs) include those with physical, learning, behavioral and intellectual disability, autism, visual, hearing and/or language and communication impairments might require special equipment or personal assistance in carrying out daily activities, influencing their psychosocial and educational development (Lersilp et al., 2018).

Children with disabilities (CWDs) are among the most stigmatized groups of children around the world (Green, 2007). Caregivers and families along with CWDs become victims of discrimination, ostracism, and human rights abuse frequently perceived as normal and justified, rather than intentional and harmful (Dirth \& Branscombe, 2017). The impact of poverty, physical neglect, and social marginalization on the disabled can be devastating. Children with disabilities (CWDs) are kept secluded at their homes, denied basic rights of mobility, education, and employment. They are 
stereotyped as dependent and incompetent persons and families generally shun disclosing about such members (Daley et al., 2018). They encounter barriers to full participation in school-related, family, community, and social activities which may exclude them from health, education, and social services. As a result of such discrimination CWDs face chronic ill health, socio-economic burden, and destitution, lack basic amenities that are integral to their health and well-being (Janardhana, 2015). This seclusion of CWDs from various activities can have profound effects on their self-confidence, self-esteem, independence. It can increase a sense of isolation decrease future employment opportunities, probably push them to live in poverty. They constantly deal with greater inequalities and have to struggle with situations and things in an attempt to "fit in" among their peers without disabilities (McNicholl et al., 2019)

\section{Education for CWDs -Laws and Policies}

Education is considered a basic human right which helps individuals to live with human dignity since its inclusion in Article 26 of the Universal Declaration of Human Rights (UDHR) proclaimed by the United Nations General Assembly (United Nations, 1948). Every nation opines that creating a literate society is of paramount importance and that no nation can develop above its educational standard (Floyd et al., 2008). For this reason, they are striving towards equal access to free and proper education to all children including those with disabilities. The attainment of this objective is under the scrutiny of The Individuals with Disabilities Act that was implemented in 1975("U.S. Department of Education," n.d.) and with "No Child Left behind (NCLB)" implemented in 2001. The Individuals with Disabilities Education Act (IDEA) ensures that all children with disabilities age 0-21 years old are entitled to a free appropriate public education to meet their unique needs and prepare them for further education, employment and independent living ("Individuals with Disabilities Education Act (IDEA),"n.d.).

Even today, very large numbers of children with disabilities are excluded completely from education or are not receiving an education appropriate to their needs. The social stigma of disability, poverty, widespread negative perception, beliefs, and lack of access to education, particularly in rural regions are the reasons for exclusion of CWDs from education (Peters, 2009; Alkhateeb et al., 2016). Statistics show that in developing countries over 90\% of CWDs are not able to access schools and among those who happen to go to school only 50\% of them reach high school. Children with special needs depend entirely upon their parents for any educational support (Aldabas, 2015). The importance of education is multifaceted. To make CWDs independent and to ensure the full, effective, equitable participation of them at all levels of decision-making, quality education and lifelong learning opportunities must be provided tothem.

\section{TYPES OF EDUCATIONAL MODELS FOR CWDS}

Over the last two decades, there has been a dramatic change in the philosophies on the education of CWDs. Different approaches are used to improve the educational outcomes of children with disabilities. There are two most popular models of education for CWDs Special needs education (SEN) and inclusive education (IE).

Traditionally, the prerequisite for an "appropriate" education for all has led to the development of a separate educational system designed to meet the needs of children with disabilities. Many people argue that children with disabilities are 'special' children, with 'special educational needs' and hence must be provided with 'special' education. This conventional pedagogy involved special schools and special classes involving the segregation of children with disabilities, even in lower- and middle-income countries. The term special needs education (SEN) is often used to refer to the process of making specialist provision in special schools for CWDs that are deemed necessary. Advocates of inclusive 
education criticize SEN, as not resulting in regular classroom teachers taking responsibility for students with disabilities (Bunch \& Valeo, 2010).

To ensure equal learning opportunities for all including CWDs some researchers opined that there is a need for immediate changes and reforms in the educational system, such as changes and adjustments of the curriculum, need for teachers' training in inclusive practices (Ainscow, 2005; Persson, 2006). These strategies have led to the development of what is known as an inclusive education model. Proponents of inclusive education claim that inclusive education is the best approach within general education settings to serve CWDs (Ainscow \& Sandill, 2010). Advocates of inclusion consider that CWDs must be educated in the mainstream in the company of their peers and believe that inclusion will result in better academic performance, help them to overcome some of their challenges, result in a stronger and a more social individual leading towards the development of a stronger community(Bunch \& Valeo, 2010). Most fundamentally, inclusive education is considered to be the "least restrictive environment" for children with disabilities (Hayes and Bulat, 2017). However, CWDs, when included in general/mainstreaming education adaptations are needed to accommodate their physical, social, learning needs (Zilz \& Pang, 2019). CWDs continue to need additional support, face increased challenges in the process of acquiring education and keeping up with their typically developing peers (Burne et al.,2011).

The inclusion of CWDs in regular classrooms is an international educational reform. Many countries are moving away from segregated education systems or SEN to a more inclusive model. This is in accordance with The UN 2030 Agenda for Sustainable Development (UN, 2015) that calls for countries to 'ensure inclusive and equitable quality education and promote lifelong learning opportunities for all' (Sustainable Development Goal) (Bubpha, 2014).

Equity in education doesn't necessarily mean uniformity. Although support for the inclusion of children with disabilities in regular education gains momentum, research lags. Nevertheless, inclusive education still a controversial concept, as the concerns about the effects of inclusion are not yet answered (Sharma et al. 2008). Critics of inclusion claim that the inclusive educational model does not have the desired outcomes for children with diverse educational needs (Anastasiou \& Kauffman, 2012) They also note that, while the goal of mainstreaming is reasonable, some children may not benefit appropriately from a full inclusion program. It can elicit significant negativity from teachers, management, other professionals, and other parents. Additionally, teachers' attitude, lack of confidence and experience, could affect inclusive education of CWDs (Pappas,2018)

Several discussions about the best suitable education model for CWDs led to the conclusion that various elements from both approaches (segregation/SEN and inclusion) are to be utilized to improve educational outcomes for people with disabilities include, as one size doesn't fit for all (Kuper et al, 2018; Pappas, 2018). The type of disability and its degree of severity, emphasize the potential need for either individualized special education services or inclusive settings. Many

\section{Education and Support Services for CWDs}

Education in the first two decades of the 21 st century undoubtedly will be remembered for the several revolutionary changes and the ongoing clamor for reform it has brought in the way students study at schools and universities. Educating children with disabilities pose challenges to both families and various stakeholders involved at homes and in schools. Lack of appropriate quality education for CWDs is considered discriminatory, improving the quality of education to overcome this obstacle should be the major plan towards the education of CWDs. Many schools lack the proper equipment, do not provide the necessary logistical infrastructure, and are not equipped with specially qualified teaching staff despite the 
Legislative arrangements and that discourage these people and their families and discard them from the school system. To enhance the quality of education to CWDs special education services, including early identification and intervention of disability right at the birth, parent engagement, effective planning for each child with a disability must be provided (Resch et al., 2010).

The perspective involved in the field of education for CWDs brings with it an expectation of support services. Support services offered to CWDs and their caregivers have continued to evolve over the years. This evolutionary process focused our attention towards "Technology" that has emerged as a ray of hope for by many educators and parents striving to provide the best education for students with an extraordinary educational need (CWDs) and to make them independent and successful in their personal and professional life on par with their non-disabled peers. The field of Education has offered many promising challenges for the integration of technology into its various aspects. Despite challenges encountered Technology is still considered to play a crucial role in helping students gain more knowledge on the theoretical and practical topics imparted in the classrooms.

Children with disabilities (CWDs) may have physical, learning, behavioral, and/or communication impairments that require support systems like some kind of equipment or assistance from caregivers in carrying out their daily living activities which can have a profound impact on their psychosocial and educational development. Several research studies have found that technology access for CWDs can lead them towards independence and positive outcomes in education (Lin \& Gold, 2017). Application of technology in education is promising only when it helps in the attainment of educational goals, enhances the competency levels deployed based on the social models that support student learning and teaching competencies (Wong et al., 2008) (Alquraini \& Gut, 2012).

Currently, educating CWDs in inclusive classrooms is filled with challenges as CWDs may have difficulties in different areas like reading, listening, organizing information, or writing. These challenges can be overcome by the use of supporting or assistive technology. Technology is considered as a bridge to overcome the gap that exists in the mode of instructional requirements for children with special needs and the instructors. Some professionals support using assistive technology in the classroom while others have different perspectives of using assistive technology.

\section{What is Assistive Technology?}

Earlier in 1988 Technology-Related Assistance to Individuals with Disabilities Act—better known as the Tech Act was implemented (Alper \& Raharinirina, 2006). This act led to the implementation of technology-mediated educational pedagogy for Children with or without disabilities to enhance their learning (Bryant \& Seok, 2017). Technology that is used to facilitate an individual to participate independently and enjoy privilege extended by human rights, it is referred to as "Assistive technology (AT)". This statement is completely following the objective of The Convention of the Rights of Persons with Disabilities (CRPD) 2006 and the Standard Rules on the Equalization of Opportunities for Persons with Disabilities (Standard Rules)(Toro-Hernández et al., 2019; Borg et al., 2012). Assistive technology (AT) is a special tool designed to enhance the learning and academic performance, and longevity of all individuals not just students with special needs in the general classroom(Murchland \& Parkyn, 2010). AT is an umbrella term that describes products and services that enhance individuals 'functioning and participation; including systems, services, products, devices, equipment, and software. AT will be understood as a continuum of technological solutions (Owuor et al., 2018). 
Assistive technology, as defined in the Individuals with Disabilities Education Act (IDEA, 2004), refers to "any item, piece of equipment, or product system, whether acquired commercially off the shelf, modified, or customized, that is used to increase, maintain, or improve the functional capabilities of a child with a disability" and is a related service to be considered for students with disabilities as part of their Individualized Education Program (IEP) (IDEA, 2004, Section 300.5). As per the recommendations of occupational therapists, assistive technology is to be introduced to CWDs to overcome the persistent barriers to their participation in classroom activities(Freeman et al., 2004).

\section{What are the Strategies for using Assistive Technology?}

Strategies for providing assistive technology need to consider the principles of 5A\&Q -Availability,

- Accessibility,

- Affordability,

- Adaptability,

- Acceptability and

- Quality.

\section{Choosing the Right Assistive Technology for a Child}

Appropriate assistive technology needs of a child are determined by the assessment of the assistive technology that addresses the child's strengths as well as his or her weaknesses. IDEA (1997) mandated that the Individualized Education Plan (IEP) teams consider the technological needs of children with disabilities, including those with mild to moderate disabilities. If an AT assessment is conducted as part of a student's IEP process and it is determined that one or more AT devices and/or software are required to achieve the goals identified in the IEP, then the school system is required by law to provide the AT. In order to ensure clients, use of AT also needs selection, fitting, training, and follow-up, be safe and durable, and affordable price (Hess \& Gutierrez, 2018.). AT to be used is of three types depending on the severity of disability, low-tech, mid-tech,high-tech.

\begin{tabular}{|c|c|c|}
\hline LOW TECH & MID TECH & HIGH TECH \\
\hline $\begin{array}{l}\text { Free/Inexpensive } \\
\text { Little or no training required } \\
\text { Simple }\end{array}$ & $\begin{array}{l}\text { Moderate cost } \\
\text { Some training required } \\
\text { Somewhat sophisticated }\end{array}$ & $\begin{array}{l}\text { High cost } \\
\text { Extensive training required } \\
\text { Sophisticated }\end{array}$ \\
\hline $\begin{aligned} \text { Low } & \text { Tech Reading AT Examples } \\
\checkmark & \text { Paper based graphic } \\
& \text { organizer } \\
\checkmark & \text { Highlighter tape/pens } \\
\checkmark & \text { Highlighter reading } \\
& \text { strips } \\
\checkmark & \text { Picture symbols } \\
\checkmark & \text { Handheld magnifier } \\
\checkmark & \text { Reading guide/strip } \\
\checkmark & \text { Book holder/Slant } \\
& \text { Board } \\
\checkmark & \text { Enlarged/Modified print } \\
\checkmark & \text { Simplified Paper } \\
\checkmark & \text { Dictionary } \\
\checkmark & \text { Page Turners }\end{aligned}$ & $\begin{aligned} & \text { Mid Tech Reading AT Examples } \\
& \checkmark \text { Reading pen for text to } \\
& \text { speech } \\
& \checkmark \text { Portable eReaders } \\
& \checkmark \text { Audio/Talking Books } \\
& \checkmark \text { Headphones } \\
& \checkmark \text { Portable Dictionary } \\
& \checkmark \text { Modified Keyboard } \\
& \checkmark \text { Portable Document } \\
& \text { Camera } \\
& \checkmark \text { Switches (various) }\end{aligned}$ & $\begin{array}{cl}\text { High Tech Reading AT Examples } \\
\text { Software or Applications for } \\
\checkmark & \text { Graphic Organizing } \\
\checkmark & \text { Highlighting } \\
\checkmark & \text { Speech to Text } \\
\checkmark & \text { Screen Reading } \\
\checkmark & \text { Magnification } \\
\checkmark & \text { PDF Modifier/Converter } \\
\checkmark & \text { Text Leveling } \\
\checkmark & \text { Translation } \\
\checkmark & \text { Outlining } \\
\checkmark & \text { Removing distractions } \\
\checkmark & \text { Reading Line Guides } \\
\checkmark & \text { Picture Dictionary } \\
\checkmark & \text { Screenshot Reading } \\
\checkmark & \text { Keyboard Shortcuts } \\
\checkmark & \text { Study Guide Creation } \\
\checkmark & \text { Confusable Word } \\
\text { High Power Document Cameras } & \text { Supports }\end{array}$ \\
\hline
\end{tabular}

Image source: https://www.achievement-advantage.org/blog/reading-assistive-technology 


\section{What are the Benefits of using Assistive Technology?}

$\mathrm{AT}$ is to be utilized in the best possible manner for and by the CWDs, as it has the potential to facilitate the acquisition and expression of their knowledge, to provide access to free and appropriate education, to provide greater opportunities to be independent and to maximize their abilities to be more fully engaged in activities at home, at school, and within their communities or in a variety of environments (Copley \& Ziviani, 2004; Burgstahler, 2003). Only 10\% of those who need AT currently have access to them, and the problem is even more critical in low-and-middle-income countries (LMICs). By facilitating the participation and inclusion of children with disabilities in a variety of environments, AT may have an impact on self- esteem, self-respect, and sense of dignity (Scherer \& Glueckauf, 2005). The following are the various benefits associated with the use ofAT:

- Maximize independence in academic and employment tasks.

- Participate in classroom discussions.

- Gain access to peers, mentors, and role models

- Self-advocate

- Gain access to the full range of educational options

- Participate in experiences not otherwise possible

- Succeed in work-based learning experiences

- Secure high levels of independent living

- Prepare for transitions to college and careers

- Work side-by-side with peers.

- Master academic tasks that they cannot accomplish otherwise.

- Enter high-tech career fields.

- Participate in community and recreational activities

\section{Types of Disability and Assistive Technology used}

The Individuals with Disabilities Education Act (IDEA) requires public schools to provide special education services to eligible students. IDEA covers 13 disability categories as depicted in the table1.

\section{Examples of Assistive Technologies are}

Devices and features of devices to help perform tasks such as cooking, dressing, and grooming; specialized handles and grips, devices that extend reach, and lights on telephones and doorbells are a few examples. 
Table 1: Types of disability and the AT devices or models used

\begin{tabular}{|c|c|c|}
\hline & Type of Disability & Examples of AT \\
\hline 1 & Mobility & $\begin{array}{l}\text { Wheelchairs, scooters, walkers, canes, crutches, prosthetic devices, and orthotic } \\
\text { devices } \\
\text { Ramps, grab bars, and wider doorways to enable access to buildings, businesses, } \\
\text { and workplaces } \\
\text { Lightweight, high-performance mobility devices }\end{array}$ \\
\hline 2 & Vision & $\begin{array}{l}\text { Voice Recognition Programs, Screen Readers, and Screen Enlargement } \\
\text { Applications }\end{array}$ \\
\hline 3 & Hearing & $\begin{array}{l}\text { Hearing loop (or induction loop) systems use electromagnetic energy to transmit } \\
\text { sound. A hearing loop system involves four parts: } \\
\text { A sound source, such as a public address system, microphone, or home TV or } \\
\text { telephone } \\
\text { An amplifier } \\
\text { A thin loop of wire that encircles a room or branches out beneath carpeting A } \\
\text { receiver worn in the ears or as a headset } \\
\text { FM systems use radio signals to transmit amplified sounds. They are often used in } \\
\text { classrooms, where the instructor wears a small microphone connected to a } \\
\text { transmitter and the student wears the receiver, which is tuned to a specific } \\
\text { frequency, or channel. } \\
\text { Infrared systems use infrared light to transmit sound. A transmitter converts } \\
\text { sound into a light signal and beam it to a receiver that is worn by a listener. The } \\
\text { receiver decodes the infrared signal back to sound } \\
\text { Personal amplifiers are useful in places in which the above systems are } \\
\text { unavailable or when watching TV, being outdoors, or traveling in a car. About the } \\
\text { size of a cell phone, these devices increase sound levels and reduce background } \\
\text { noise for a listener. Some have directional microphones that can be angled toward } \\
\text { a speaker or other source of the sound. As with other ALDs, the amplified sound } \\
\text { can be picked up by a receiver that the listener is wearing, either as a headset or as } \\
\text { earbuds. }\end{array}$ \\
\hline 4 & Communication & $\begin{array}{l}\text { Augmentative and alternative communication (AAC) devices help people with } \\
\text { communication disorders to express themselves. These devices can range from a } \\
\text { simple picture board to a computer program that synthesizes speech from text. } \\
\text { Alerting devices connect to a doorbell, telephone, or alarm that emits a loud sound } \\
\text { or blinking light to let someone with hearing loss know that an event is taking } \\
\text { place. } \\
\text { Speech-generating devices go one step further by translating words or pictures into } \\
\text { speech. Some models allow users to choose from several different voices, such as } \\
\text { male or female, child or adult, and even some regional accents. } \\
\text { Some devices employ a vocabulary of prerecorded words while others have an } \\
\text { unlimited vocabulary, synthesizing speech as words are typed in. Software } \\
\text { programs that convert personal computers into speaking devices are alsoavailable. }\end{array}$ \\
\hline 5 & Cognition & $\begin{array}{l}\text { The simplest AAC device is a picture board or touch screen that uses pictures or } \\
\text { symbols of typical items and activities that make up a person's daily life. For } \\
\text { example, a person might touch the image of a glass to ask for a drink. Many } \\
\text { picture boards can be customized and expanded based on a person's age, } \\
\text { education, occupation, and interests. } \\
\text { Keyboards, touch screens, and sometimes a person's limited speech may be used } \\
\text { to communicate desired words. Some devices employ a text display. The display } \\
\text { panel typically faces outward so that two people can exchange information while } \\
\text { facing each other. Spelling and word prediction software can make it faster and } \\
\text { easier to enter information. } \\
\text { computer or electrical assistive devices, to help people with memory, attention, or } \\
\text { other challenges in their thinking skills }\end{array}$ \\
\hline 6 & Learning & $\begin{array}{l}\text { Automatic page-turners, book holders, and adapted pencil grips, smartboard, I } \\
\text { Pad and smart I phones. }\end{array}$ \\
\hline
\end{tabular}




\section{FUTURE ASSISTIVE TECHNOLOGY IN MENA COUNTRIES}

Healthcare systems around the world are under increased pressure to deliver high-quality and efficient care to growing populations, but the financial and human resources to deliver that care is becoming increasingly stretched. At the same time, disability among children is increasing such as cognitive, physical, and neurodevelopment disorders since 2016, the Access Abilities Expo which was held from February 9-11, 2016, at the Dubai International Convention and Exhibition Centre. Therefore, more than 50 million people with disabilities across the Middle East stand to benefit from the world's latest Robotics and Assistive Technology products from over 30 countries, which will be showcased at Access Abilities Expo that was being held under the patronage of His Highness Sheikh Ahmed Bin Saeed Al Maktoum, President of the Dubai Civil Aviation Authority, Chairman of Dubai Airports, Chairman and Chief Executive of Emirates Airline and Group.

The exhibitors showed the latest technology catering to a wide spectrum of disabilities and disorders including neurological and physical disabilities. These products include aids for leisure and sports for the disabled such as running prostheses for recreational athletes, leg prosthesis systems that virtually make replication of physiological human gait possible to pre-hospital medical equipment, folding electric mobility scooters, specially designed cars allowing driving directly from the wheelchair, high-definition silicone, orthotic, mobility devices, power wheelchairs, innovative solutions for sound sensory stimulation, voice synthesizers, Braille readers, and wireless monitoring devices and special tools and software that enhances language and learning through a simple reading protocol

\section{WHAT ARE THE BARRIERS TO ASSISTIVE TECHNOLOGY?}

Given the gaps in knowledge and scarcity of specific regional data, it is difficult to assess the situation in the Region regarding access to assistive technology for those in need. However, several studies and reports present data on the prevalence of health conditions that may affect functional capacity and could thus help draw the regional context underlying the need for assistive technology.

Among barriers is a lack of suitable learning environment which refers to the diverse physical locations, contexts, and cultures in which students learn [Abbott, 2014]. Some researchers found that the learning environment, especially the classroom, had a positive impact on the academic performances of the students [Barrett, et al., 2013, Barrett, et al., 2015], and it is very important for those with special needs. A positive learning environment can facilitate the performance areas in daily life, education, play, leisure, and social participation for the students. On the other hand, a negative learning environment can obstruct their performances and skills.

Additionally, a lot of barriers to implementing AT are reported to be in the form of lack of awareness, lack of governance including legislation, policies, and national programs' absence of services and products. Moreover, decreasing human resources and the presence of financial barriers which facilitate buying the AT equipment or funding for AT.

\section{CONCLUSIONS AND RECOMMENDATIONS}

- Overall, following the findings of Nierling et al. (2018) who reported that "people with disabilities have an open and optimistic attitude towards new and emerging technologies" [11] (p. 3). As RB states: "Really good assistive technology is life-changing for all disabled children. Addressing the fact, that the global assistive technology community has moved from a focus on assistive products to embrace 
assistive technology systems, coupled with "the need for user involvement in all aspects of research, policy development, system design, and service provision. New technologies are used for building up hopes for a better future. Thus, and according to the findings of the UNDP (2012: 144) several tasks have to be managed to advance these MENA societies as following:

- Reviewing management institutions and their readiness to use and absorb technology particularly in the field of education and training.

- Emphasizing intellectual property rights and reviewing the legislation and laws governing the use of technology in a way that achieves its deployment and supports the freedom of using it.

- Training on quality systems and enabling individuals to use technology efficiently.

- Encouraging foreign investment to achieve a quantum leap [in terms of technological and ICT advancement], especially in the areas needing highly qualified cadres.

- Developing major projects to create a critical mass to deploy, employ, and produce technology in schools, universities, homes, productive institutions, government, and public life in all areas.

- The industrial Internet can boost productivity and efficiency to help deliver lower and more affordable costs through the use of wireless access to cloud data and sensors;

- Advanced manufacturing techniques are expected to bring greater speed, flexibility, and innovation to the shop floor, enabling the rise of micro-factories and high-value artisanal workshops;

- The "global brain" can enhance industrial capacity by bringing technologies and workforces together between different countries to collaborate on ideas (Rostom2015).

- These three potentials are all based on intensive collaboration and connectivity, which are therefore key prerequisites for such change. In this optimistic view, such an innovation process will unlock

\section{DISCLOSURE STATEMENT}

No potential conflict of interest was reported by the authors.

\section{REFERENCES}

1. Abbott S.,(2014)Ed., "Hidden curriculum," The glossary of Education reform, August,http://edglossary.org/hidden-curriculum

2. Green SE. (2007). "'We" retired, not sad ": Benefits and burdens of mothering a child with a disability. 64, 150-163. https://doi.org/10.1016/j.socscimed.2006.08.025

3. Ainscow, M. E. L. (2005). DEVELOPING INCLUSIVE EDUCATION SYSTEMS: WHAT. 109-124. https://doi.org/10.1007/s10833-005-1298-4

4. Aldabas, R. A. (2015). Special Education in Saudi Arabia: History and Areas for Reform. June1158-1167.

5. Al-Dosari, Saad (2016), "Social Media Usage in the Middle East", in Arab News, 29 February,http://www.arabnews.com/node/888271

6. Alkhateeb, J. M., Hadidi, M. S., \& Alkhateeb, A. J. (2016). Research in Developmental Disabilities Review article Inclusion of children with developmental disabilities in Arab countries: A review of the research literature from 1990 to 2014. Research in 
Developmental Disabilities, 49-50, 60-75. https://doi.org/10.1016/j.ridd.2015.11.005

7. Al Lawati, S. (201, July 15). Mentally disabled children in the Middle East and their integration into society. Retrieved April 9 , 2020, from

http://www.middleeasthealthmag.com/cgibin/index.cgi?http://www.middleeasthealthmag.com/jul2011/feature5.htm

8. Alper, S., \& Raharinirina, S. (2006). Assistive Technology for Individuals with Disabilities: A Review and Synthesis of the Literature. Journal of Special Education Technology, 21(2), 47-64.https://doi.org/10.1177/016264340602100204

9. Alquraini, T., \& Gut, D. (2012). CRITICAL COMPONENTS OF SUCCESSFUL INCLUSION OF STUDENTS WITH SEVERE. $27,42-59$.

10. Anastasiou, D., \& Kauffman, J. M. (2012). Disability as Cultural Difference: Implications for Special Education. 33(3). https://doi.org/10.1177/0741932510383163

11. Annunziata, Marco and Rania Rostom (2015), Mapping the Future of Work in MENAT: A 2015Outlook, GE Report, http://middleeast.geblogs.com/download/Mapping-the-future-of-work-inMENAT-A-2015-Outlook.pdf

12. Barrett P., Y. Zhang, J. Moffat, and K. Kobbacy, (2013)"A holistic, multi-level analysis identifying the impact of classroom design on pupils' learning," Building and Environment, vol. 59, pp. 678-689,. View at Publisher Site | GoogleScholar

13. Barrett P., F. Davies, Y. Zhang, and L. Barrett, (2015)"The impact of classroom design on pupils' learning: final results of a holistic, multi-level analysis," Building and Environment, vol. 89, pp. 118-133,.View at Publisher Site | GoogleScholar

14. Borg, J., Larsson, S., Östergren, P. O., Rahman, A. A., Bari, N., \& Khan, A. N. (2012). Assistive technology use and human rights enjoyment: A cross-sectional study in Bangladesh. BMC International Health and Human Rights, 12(1). https://doi.org/10.1186/1472-698X-12-18

15. Borg, J, Rosangela Berman-Bieler, Chapel Khasnabis, Gopal Mitra, William N Myhill, and Deepti Samant Raja. (2015, July 1). Assistive Technology for Children with Disabilities: Creating Opportunities for Education, Inclusion, and Participation. Retrieved April 9, 2020, fromhttps://www.unicef.org/disabilities/files/Assistive-Tech-Web.pdf

16. Bryant, B. R., \& Seok, S. (2017). Introduction to the special series: Technology and disabilities in education. Assistive Technology, 00(00), 1-2.https://doi.org/10.1080/10400435.2016.1230154

17. Bubpha, S. (2014). Models of Inclusive Education: One Size Does Not Fit All. 3(2),328-334.

18. Bunch, G., \& Valeo, A. (2010). Student attitudes toward peers with disabilities in inclusive and special Student attitudes toward peers with disabilities in inclusive and special education schools. December 2014, 37-41. https://doi.org/10.1080/0968759032000155640

19. Burgstahler, S. (2003). The Role of Technology in Preparing Youth with Disabilities for Postsecondary Education and Employment. Journal of Special Education Technology, 18(4), 7-19.https://doi.org/10.1177/016264340301800401

20. Burne, B., Knafelc, V., Melonis, M., \& Heyn, P. C. (2011). The use and application of assistive technology to promote literacy in early childhood: A systematic review. Disability and Rehabilitation: Assistive Technology, 6(3), $207-213$. https://doi.org/10.3109/17483107.2010.522684

21. Copley, J., \& Ziviani, J. (2004). Barriers to the use of assistive technology for children with multiple disabilities. Occupational Therapy International, 11(4), 229-243.https://doi.org/10.1002/oti.213

22. Daley, A., Phipps, S., \& Branscombe, N. R. (2018). SSM - Population Health The social complexities of disability:Discrimination, belonging, and life satisfaction among Canadian youth. SSM - Population Health, 5(February), 5563. https://doi.org/10.1016/j.ssmph.2018.05.003 
23. Dirth, T. P., \& Branscombe, N. R. (2017). Disability Models Affect Disability Policy Support through Awareness of Structural Discrimination *. 73(2), 413-442.https://doi.org/10.1111/josi.12224

24. Floyd, K., Smith Canter, L., Jeffs, T., \& Judge, S. (2008). Assistive Technology and Emergent Literacy for Preschoolers: A Literature Review. Assistive Technology Outcomes and Benefits, 5(1),92-102.

25. Freeman, A. R., MacKinnon, J. R., \& Miller, L. T. (2004). Assistive technology and handwriting problems: What do occupational therapists recommend? Canadian Journal of Occupational Therapy, 71(3), 150-160. https://doi.org/10.1177/000841740407100305

26. Hayes, A. M, \& Bulat, J. (2017, July 15). Disabilities Inclusive Education Systems and Policies Guide for Low-and MiddleIncome Countries. RTI Press Publication No. OP-0043-1707. ResearchTriangle Park, NC: RTI Press. https://doi.org/10.3768/rtipress.2017.op.0043.1707.Retrieved

April 11, 2020,

27. Hess, J., \& Gutierrez, A.-M. (2018.). Assistive Technology 101 Get informed about assistive technology for your child. Retrieved April 12, 2020, fromhttps://www.ctdinstitute.org/sites/default/files/file_attachments/CTD-AT101-V4.pdf

28. Individuals with Disabilities Education Act (IDEA). (n.d.). Retrieved April 7, 2020, from https://www.apa.org/advocacy/education/idea/

29. Janardhana, N. (2015). Discrimination against differently-abled children among rural communities in India: Need for action. 6(1). https://doi.org/10.4103/0976-9668.149070

30. Kostanjsek, N. (2011). Use of the International Classification of Functioning, Disability, and Health (ICF) as a conceptual framework and common language for disability statistics and health information systems. BMC Public Health, 11(SUPPL. 4), 2-7. https://doi.org/10.1186/1471-2458-11-S4-S3

31. Krahn, G. L., Walker, D. K., \& Correa-de-araujo, R. (2015). Persons with Disabilities as an Unrecognized Health Disparity Population. 105, 198-206.https://doi.org/10.2105/AJPH.2014.302182

32. Lin, S. C., \& Gold, R. S. (2017). Assistive Technology Needs, Functional Difficulties, and Services Utilization and Coordination of Children with Developmental Disabilities in the United States Assistive Technology Needs, Functional Difficulties, and Services Utilization and Coordinate. Assistive Technology, 00(00), 1-7. https://doi.org/10.1080/10400435.2016.1265023

33. McNicholl, A., Casey, H., Desmond, D., \& Gallagher, P. (2019). The impact of assistive technology use for students with disabilities in higher education: a systematic review. Disability and Rehabilitation: Assistive Technology, 0(0), 1-14. https://doi.org/10.1080/17483107.2019.1642395

34. Mirkin, B. (2010). Population levels, trends, and policies in the Arab Region: Challenges and opportunities, Arab Human Development Report. United Nations Development Programme,1-41.

35. Murchland, S., \& Parkyn, H. (2010). Using assistive technology for schoolwork: the experience of children with physical disabilities. 5(November), 438-447.https://doi.org/10.3109/17483107.2010.48177

36. Nierling,L.;Maia,M.J.F.;Hennen,L.;Wolbring,G.;Bratan,T.;Kukk,P.;Cas,J.;Capari,L.;Krieger-Lamina,J.;Mordini,

37. E. Assistive Technologies for People with Disabilities. Part. III: Perspectives on Assistive Technologies; EPRS European Parliamentary Research Service: Brussels, Belgium, 2018.

38. Owuor, J., Larkan, F., Kayabu, B., Fitzgerald, G., Sheaf, G., Dinsmore, J., McConkey, R., Clarke, M., \& Maclachlan, M. (2018). Does assistive technology contribute to social inclusion for people with intellectual disabilities? A systematic review protocol. BMJ Open, 8(2).https://doi.org/10.1136/bmjopen-2017-017533 
39. Pappas, M. A. (2018). Policies,Practices, and Attitudes toward Inclusive Education: The Case of Greece. Ainscow 2005. https://doi.org/10.3390/socsci7060090

40. Peters, S. (2009). Review of marginalization of people with disabilities in Lebanon, Syria, and Jordan. Retrieved April 9, 2020, from http://www.unesco.org/new/fileadmin/MULTIMEDIA/FIELD/Beirut/pdf/Background\%20paper\%20EFA\%202010Marginalization\%20in\%20Jordan\%20Syria\%20and\%20Lebanon.pdf

40. Persson, B., \& Persson, B. (2006). Pathways to Inclusion: 5(2), 152-158. https://doi.org/10.2304/eerj.2006.5.2.152

41. Resch, J. A., Mireles, G., Benz, M. R., Grenwelge, C., Peterson, R., \& Zhang, D. (2010). Giving Parents a Voice: A Qualitative Study of the Challenges Experienced by Parents of Children with Disabilities. 55(2), 139-150. https://doi.org/10.1037/a0019473

42. Rostom, Rania (2015), "3 Disruptive Innovations That Are Changing the Middle East", in World Economic Forum Articles, 22 May,https://www.weforum.org/agenda/2015/05/3-disruptiveinnovations-that-are-changing-the-middle-east

43. Scherer, M. J., \& Glueckauf, R. (2005). Assessing the benefits of assistive technologies for activities and participation. Rehabilitation Psychology, 50(2), 132-141.https://doi.org/10.1037/0090-5550.50.2.132

44. The global burden of disease: 2004 update. (n.d.). Retrieved April 8, 2020, from https://www.who.int/healthinfo/global_burden_disease/2004_report_update/en

45. Toro-Hernández, M. L., Kankipati, P., Goldberg, M., Contepomi, S., Tsukimoto, D. R., \& Bray, N. (2019). Appropriate Assistive Technology for Developing Countries. Physical Medicine and Rehabilitation Clinics of North America, 30(4), 847865. https://doi.org/10.1016/j.pmr.2019.07.008

46. United Nations. (1948). Universal Declaration of Human Rights Preamble. United Nations Declaration of Human Rights. https://www.ohchr.org/EN/UDHR/Documents/UDHR_Translations/eng.pdf

47. United Nations. Convention on the rights of persons with disabilities. 2006.Available at: http://www.un.org/disabilities/documents/convention/convoptprote.pdf

48. Universal Declaration of Human Rights Preamble. United Nations Declaration of Human Rights. (n.d.). Retrieved April 7 , 2020, fromhttps://www.un.org/en/universal-declaration-human-rights/

49. UNDP (2012), Arab Knowledge Report 2010/2011. Preparing Future Generations for the Knowledge Society, http://arabhdr.org/akr.

50. U.S. Department of Education. (n.d.). Retrieved April $\quad$ 7, 2020, from

51. World report on disability. (n.d.). Retrieved April 8, 2020, fromhttps://www.who.int/disabilities/world_report/2011/report.pdf

52. World Health Organization. (2007). International classification of functioning, disability, and health: children and youth version: ICF-CY. World Health Organization.https://apps.who.int/iris/handle/10665/43737

53. Wong, E. M. L., Li, S. S. C., Choi, T., \& Lee, T. (2008). Insights into Innovative Classroom Practices with ICT: Identifying the Impetus for Change Research framework. 11,248-265.

54. Zilz, W., \& Pang, Y. (2019). Application of assistive technology in inclusive classrooms. Disability and Rehabilitation: Assistive Technology, O(0), 1-3.https://doi.org/10.1080/17483107.2019.1695963

55. Thakur, Neelam. "Aetiology of Mild and Serious Intellectual Disabilities/Mr without Any Identified Genetic Cause." International Journal of Environment, Ecology, Family and Urban Studies (IJEEFUS) 8.3(2018):25-34

56. Upreti, Rashmi, and Ritu Singh. "Coping Strategies for Perceived Stress Among Parents of Mentally Challenged Children 

Region: A literature Review

Across their Gender." International Journal of Humanities and Social Sciences (IJHSS) 5.6(2016):213-220

57. Wang, Nien-Tsan, Y. L. Chen, and Y. C. Hsu. "Assistive design of cursors for low vision users." International Journal of Communication and Media Studies (IJCMS) 6.2 (2016):1-6.

58. Gaikwad, Rakesh Sayaji, and Girish Kamal Gautam. "Image Processing Based Colour Pointer to Drive Wheelchair Using Open CV." International Journal of Electronics, Communication \& Instrumentation Engineering Research and Development (IJECIERD) 5.3 (2015):19-26 

